Supplementary information for the paper:

\title{
A New Facile Synthesis of Tertiary Dithioesters
}

by Angelo Alberti, ${ }^{\dagger}$ Massimo Benaglia, ${ }^{* \dagger}{ }^{\dagger}$ Michele Laus $^{\ddagger}$ and Katia Sparnacci ${ }^{\ddagger}$

electronically submitted to The Journal of Organic Chemistry on 09.07.2002

\section{Table of contents}

Figure S2: Compound $1-{ }^{13} \mathrm{C}$ NMR

Figure S3: Compound $1-{ }^{1} \mathrm{H}$ NMR

Figure S4: Compound $1-{ }^{31} \mathrm{P}$ NMR

Figure S5: Compound 2a $-{ }^{13} \mathrm{C}$ NMR

Figure S6: Compound $\mathbf{2 a}-{ }^{1} \mathrm{H}$ NMR

Figure S7: Compound 2a $-{ }^{31} \mathrm{P}$ NMR

Figure S8: Compound $\mathbf{2 b}-{ }^{13} \mathrm{C}$ NMR

Figure S9: Compound $\mathbf{2 b}-{ }^{1} \mathrm{H}$ NMR

Figure S10: Compound $\mathbf{2 b}-{ }^{31} \mathrm{P}$ NMR

Figure S11: Compound 2c $-{ }^{13} \mathrm{C}$ NMR

Figure S12: Compound $2 \mathrm{c}-{ }^{1} \mathrm{H}$ NMR

Figure S13: Compound 2c $-{ }^{31} \mathrm{P}$ NMR

Figure S14: Compound 2d $-{ }^{13} \mathrm{C}$ NMR

Figure S15: Compound 2d $-{ }^{1} \mathrm{H}$ NMR

Figure S16: Compound 2d $-{ }^{31} \mathrm{P}$ NMR

Figure S17: Compound $4-{ }^{13} \mathrm{C}$ NMR

Figure S18: Compound $4-{ }^{1} \mathrm{H}$ NMR

Figure S19: Compound $4-{ }^{31} \mathrm{P}$ NMR

Figure S20: Compound $6-{ }^{13} \mathrm{C}$ NMR

Figure S21: Compound $6-{ }^{1} \mathrm{H}$ NMR 


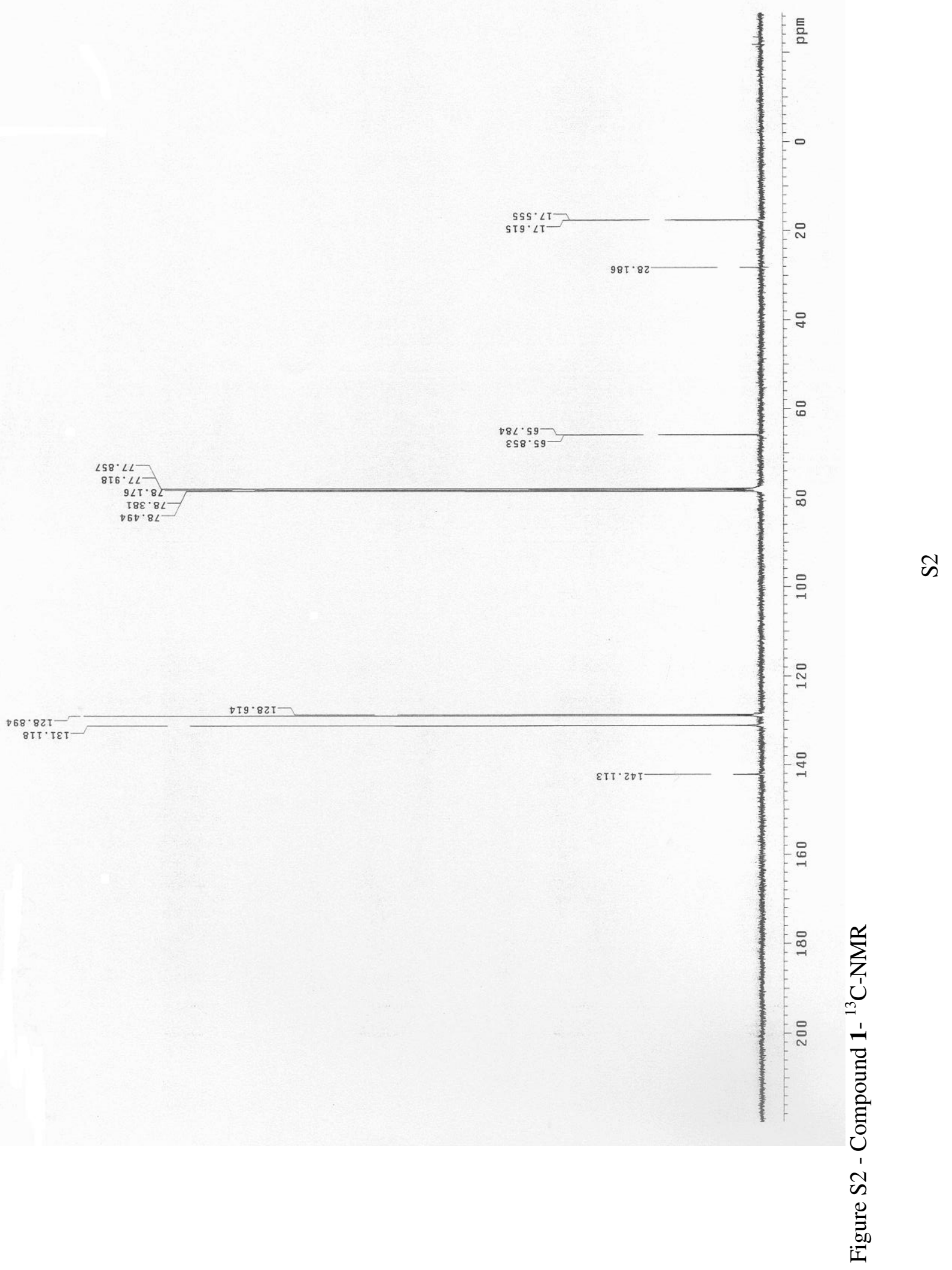




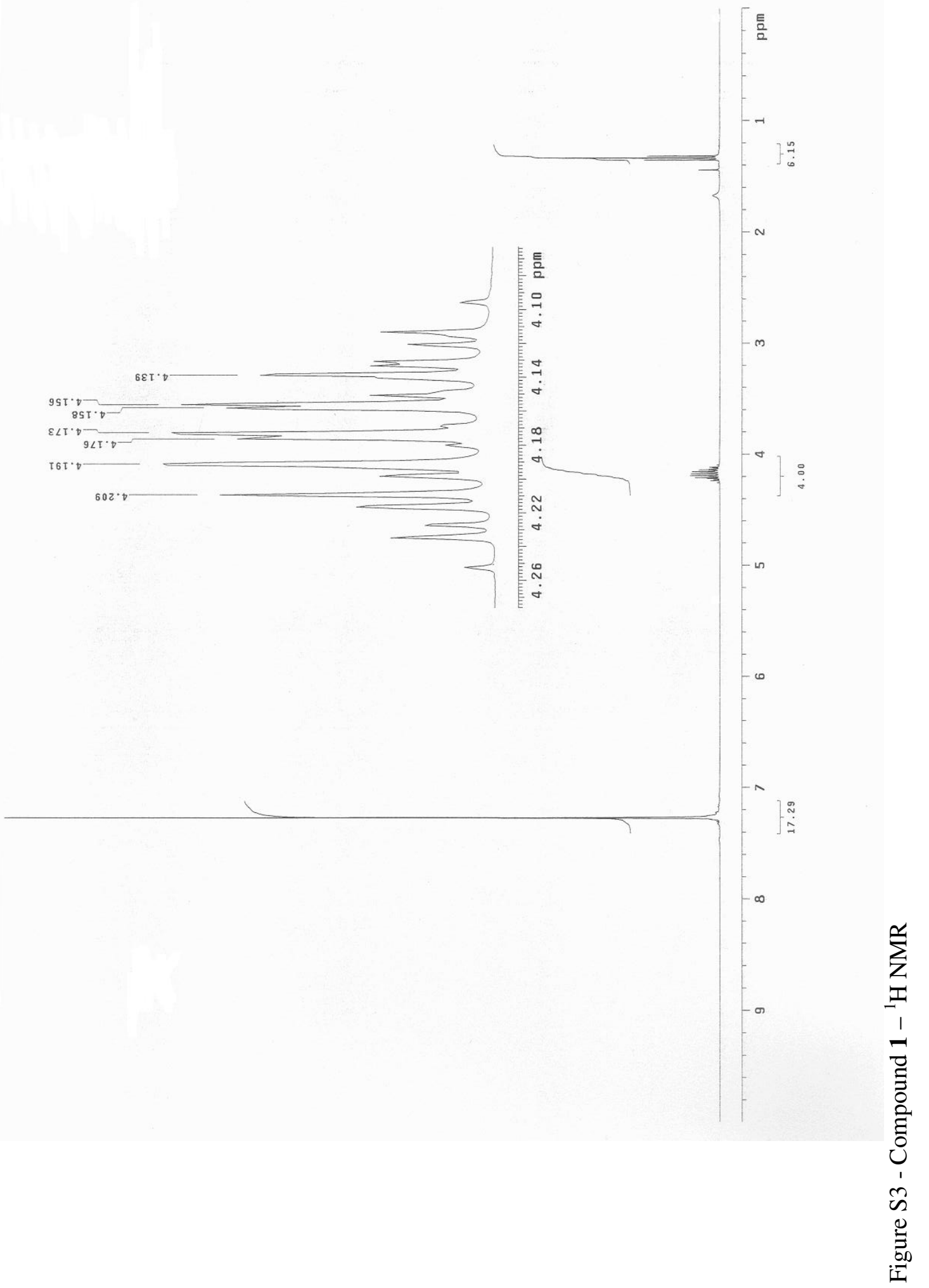




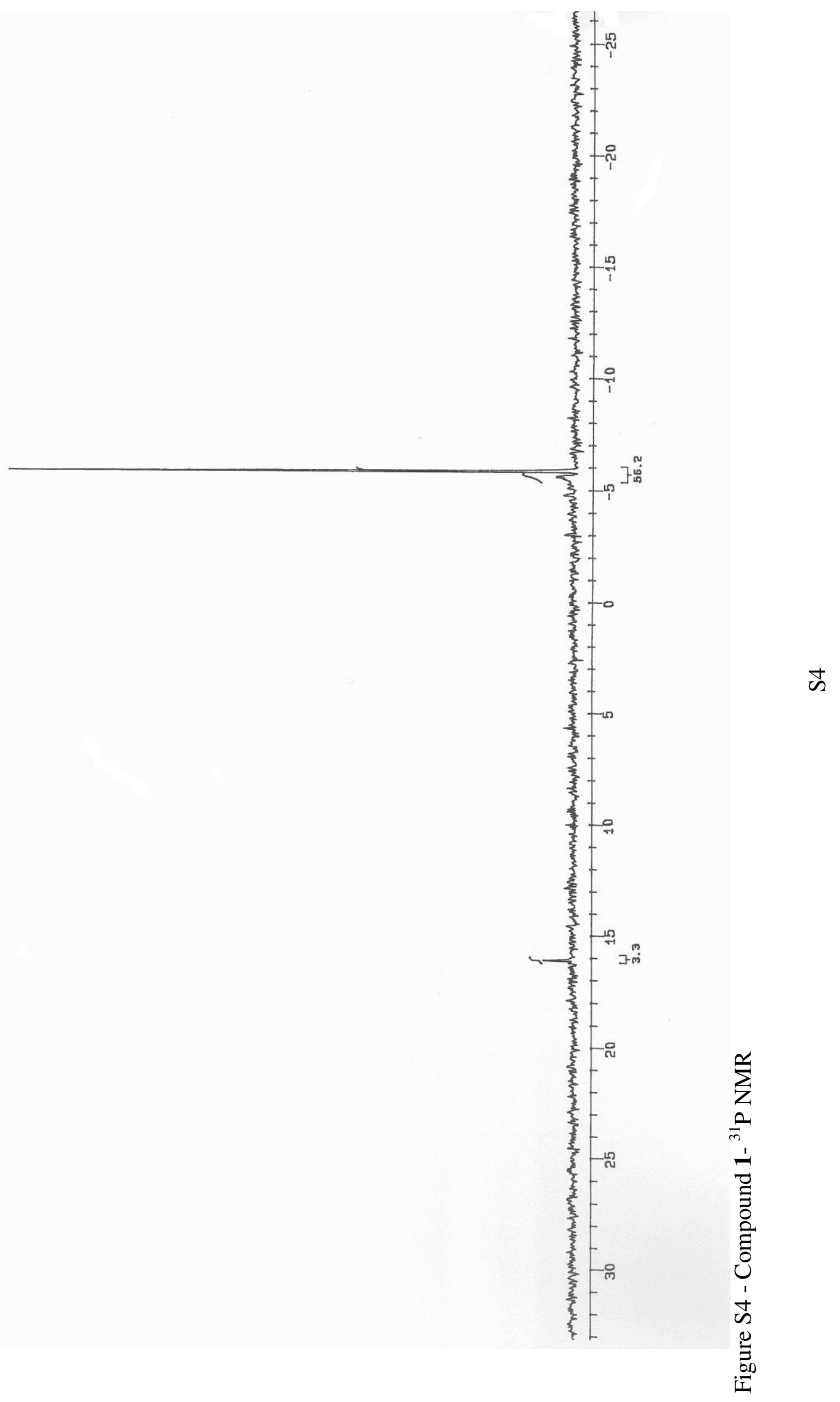




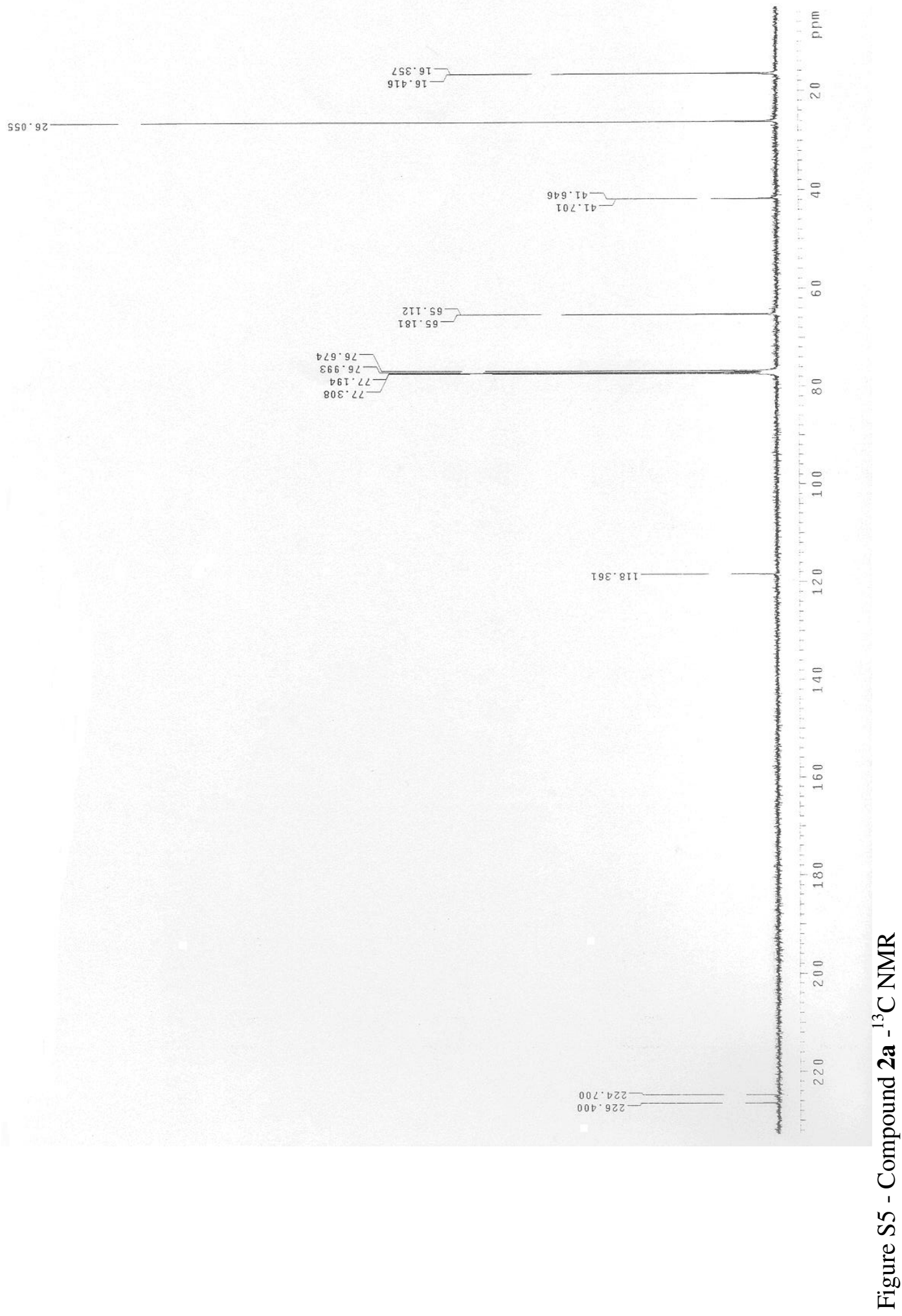




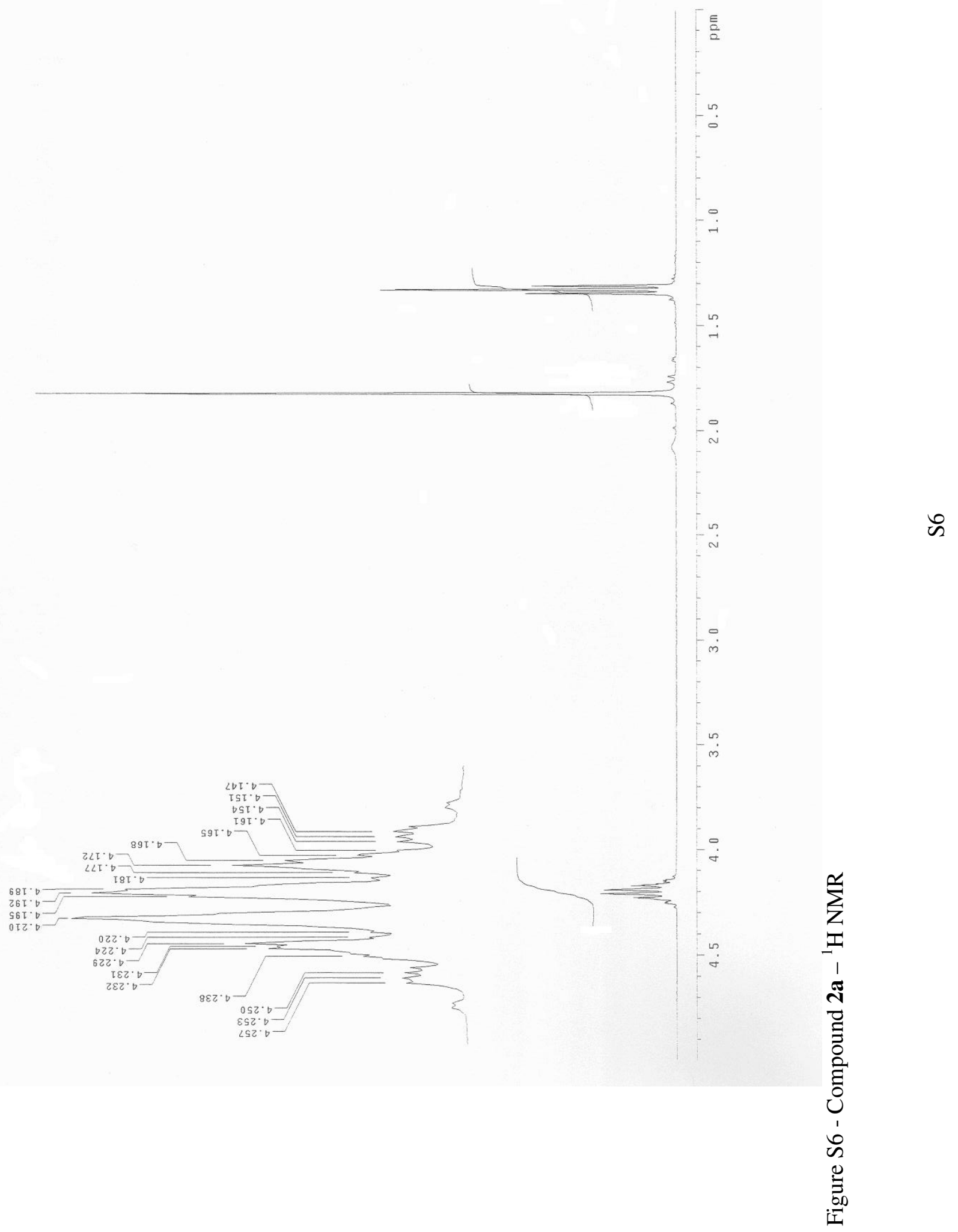




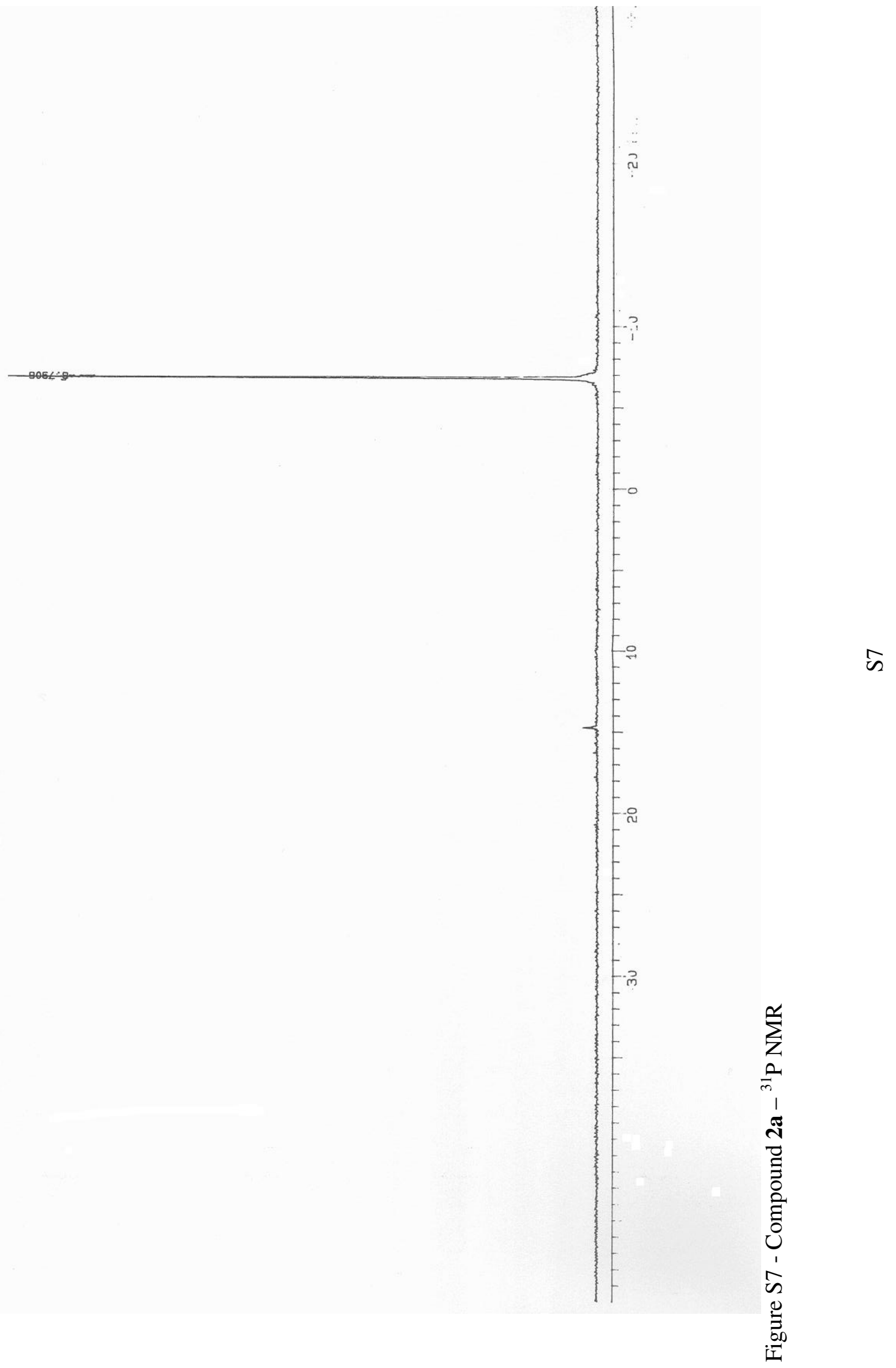




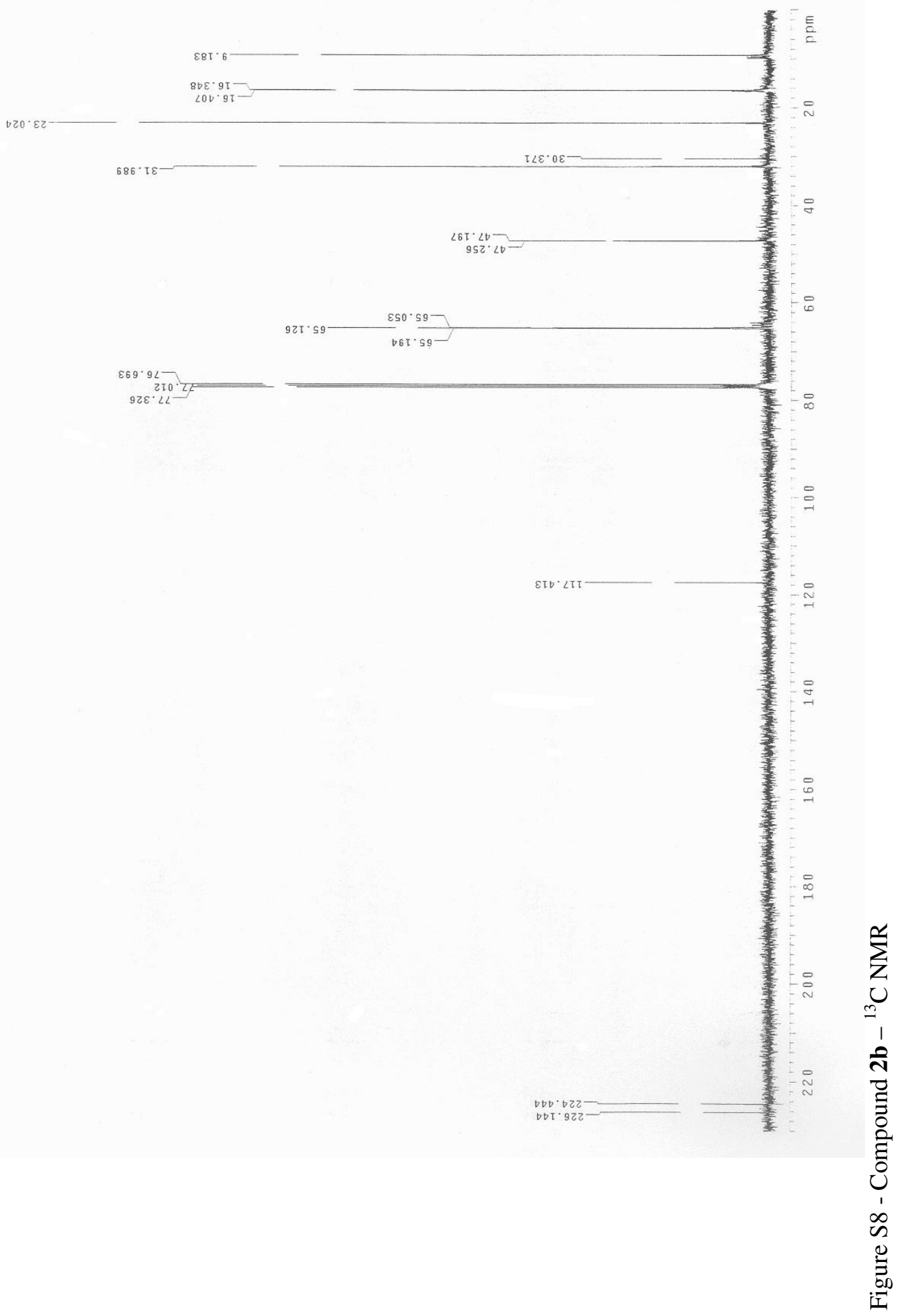




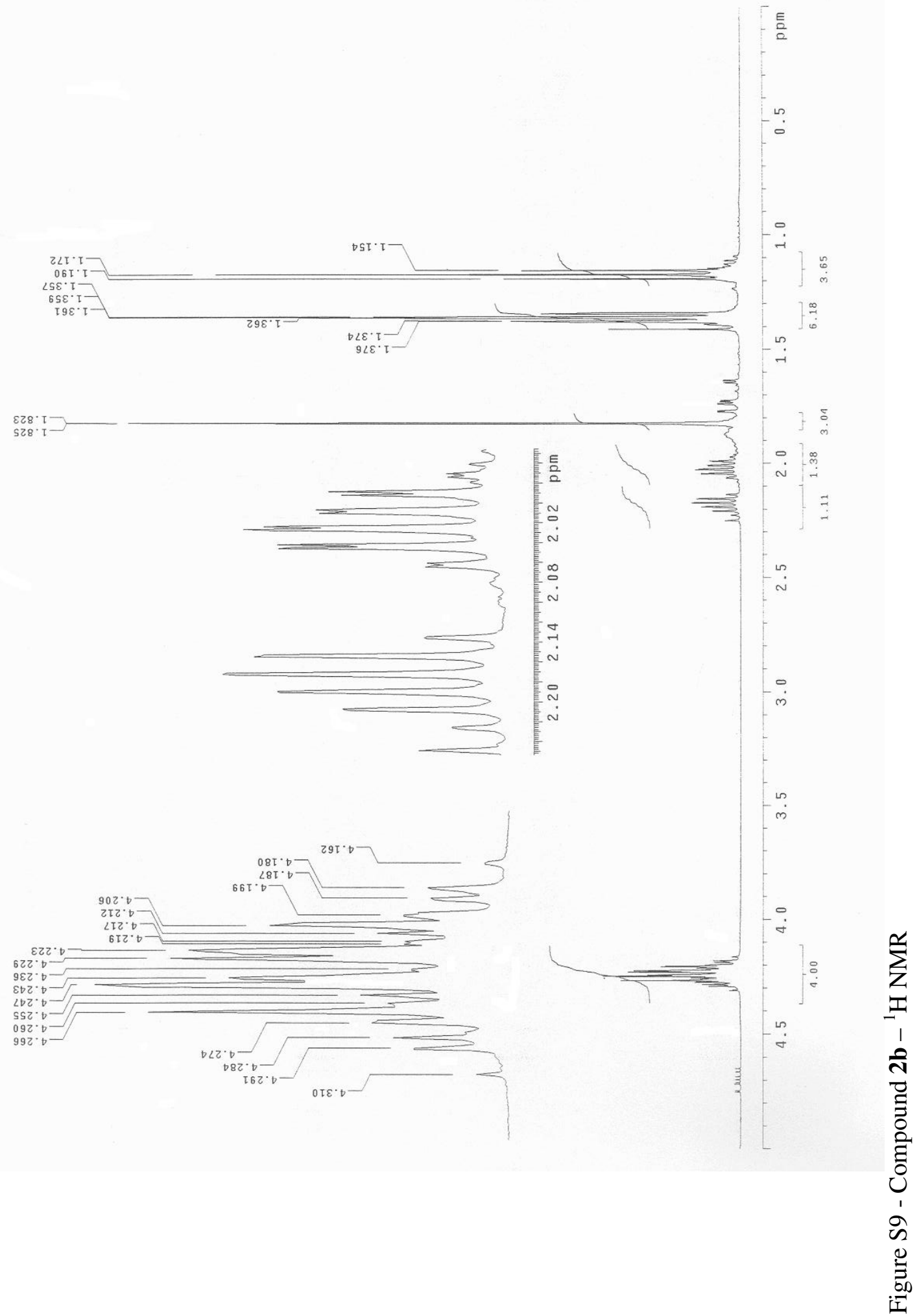




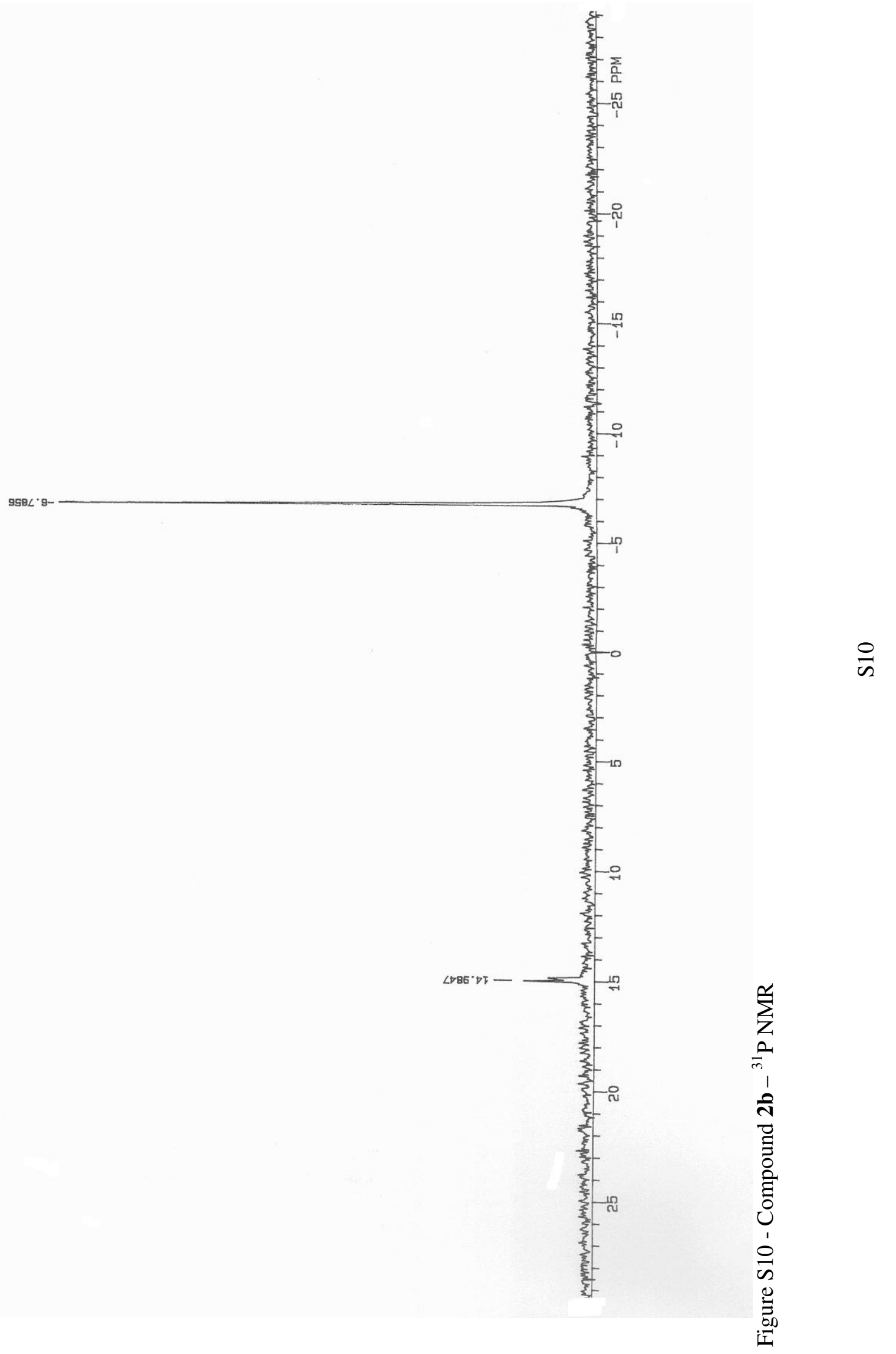




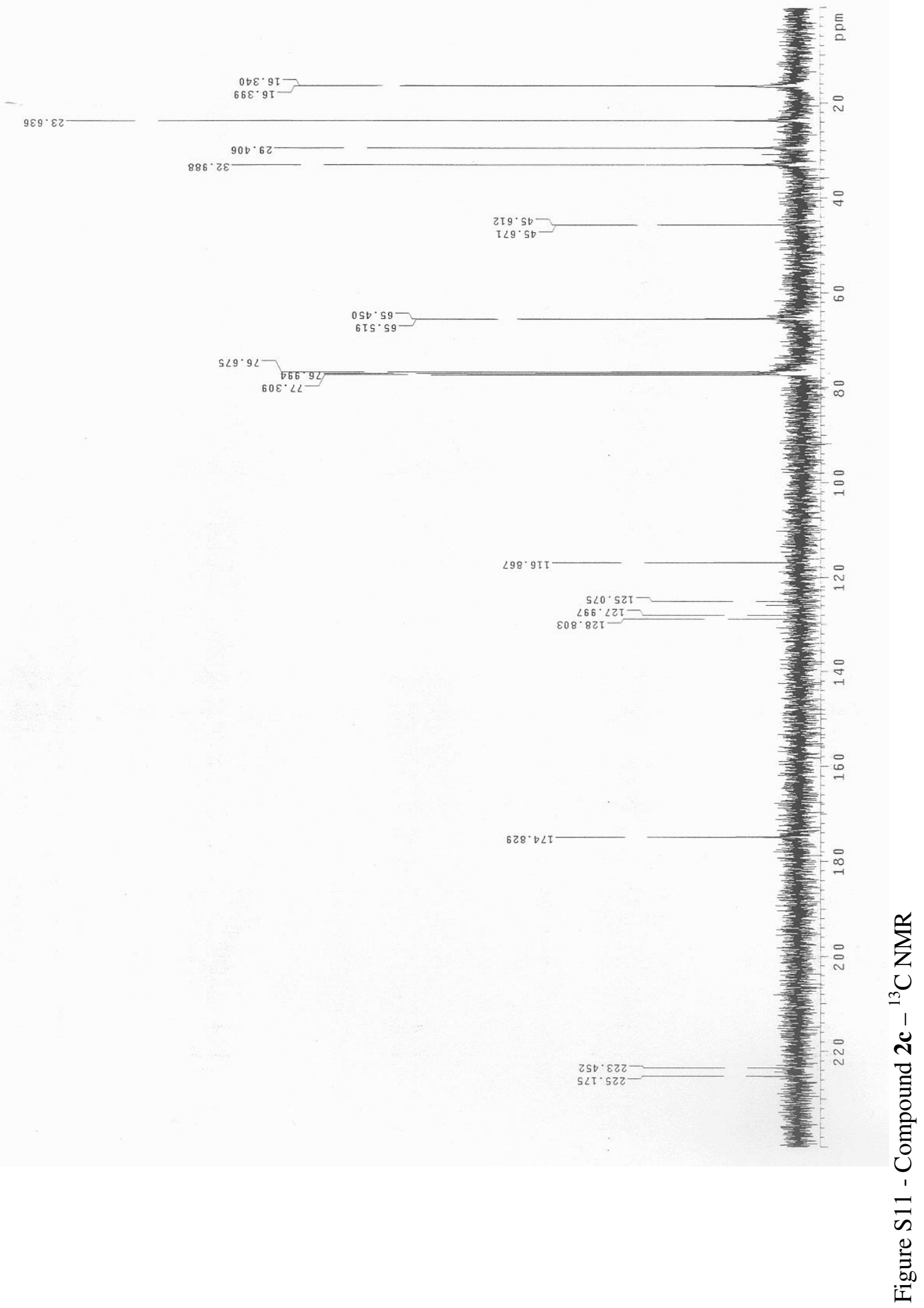




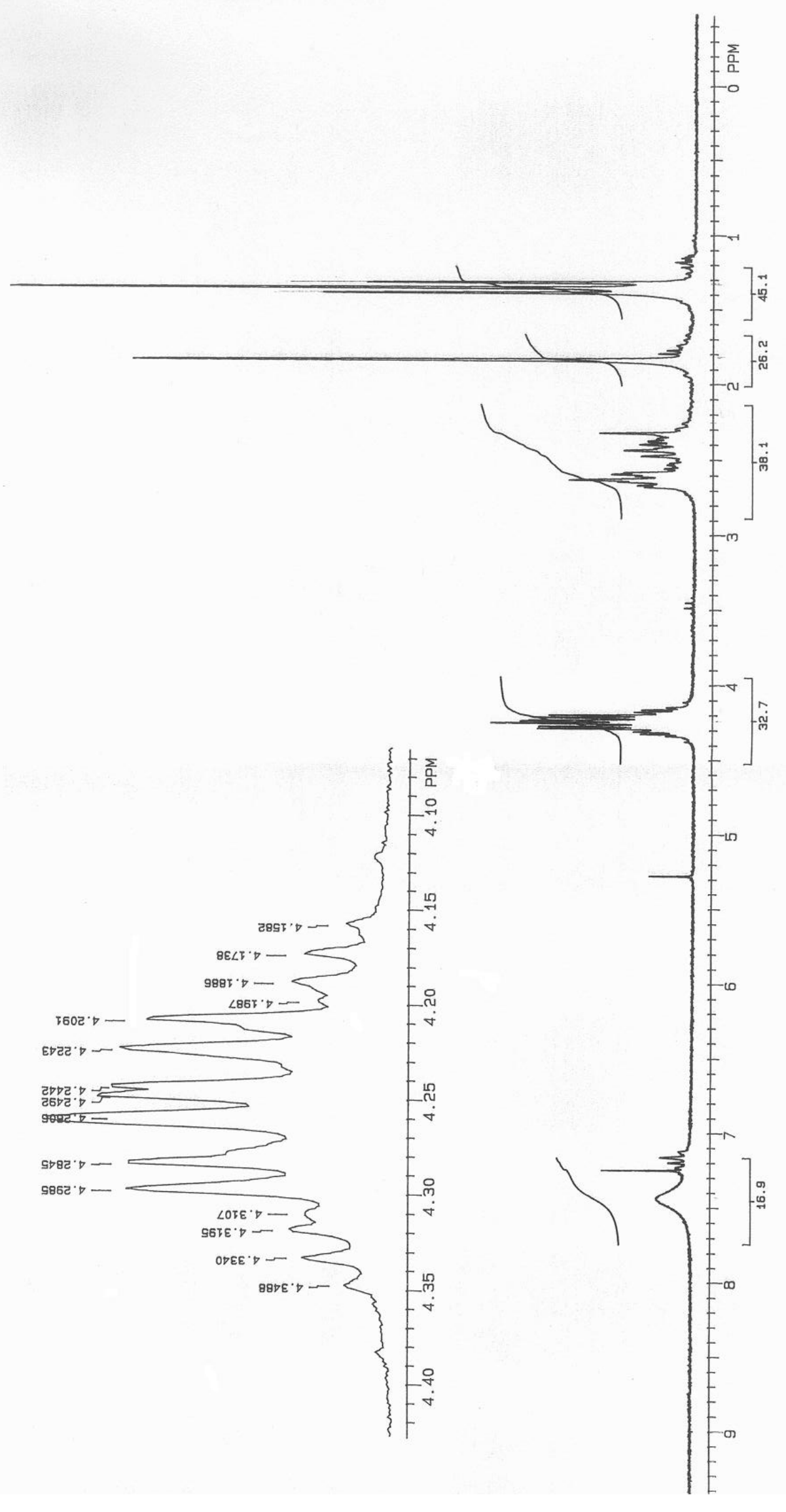

$\frac{N}{n}$

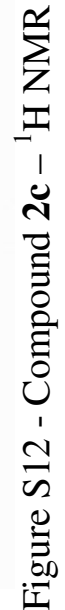




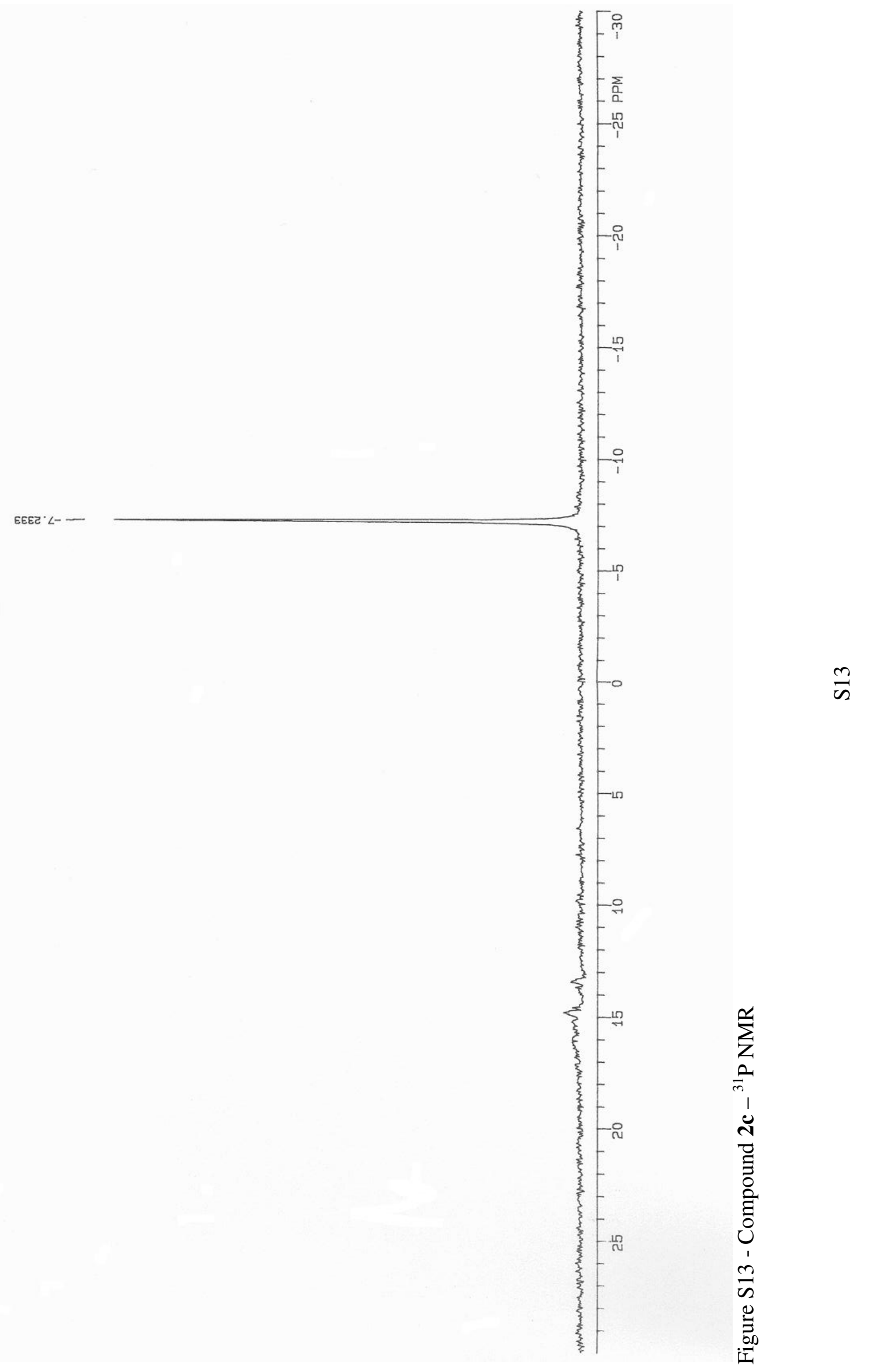




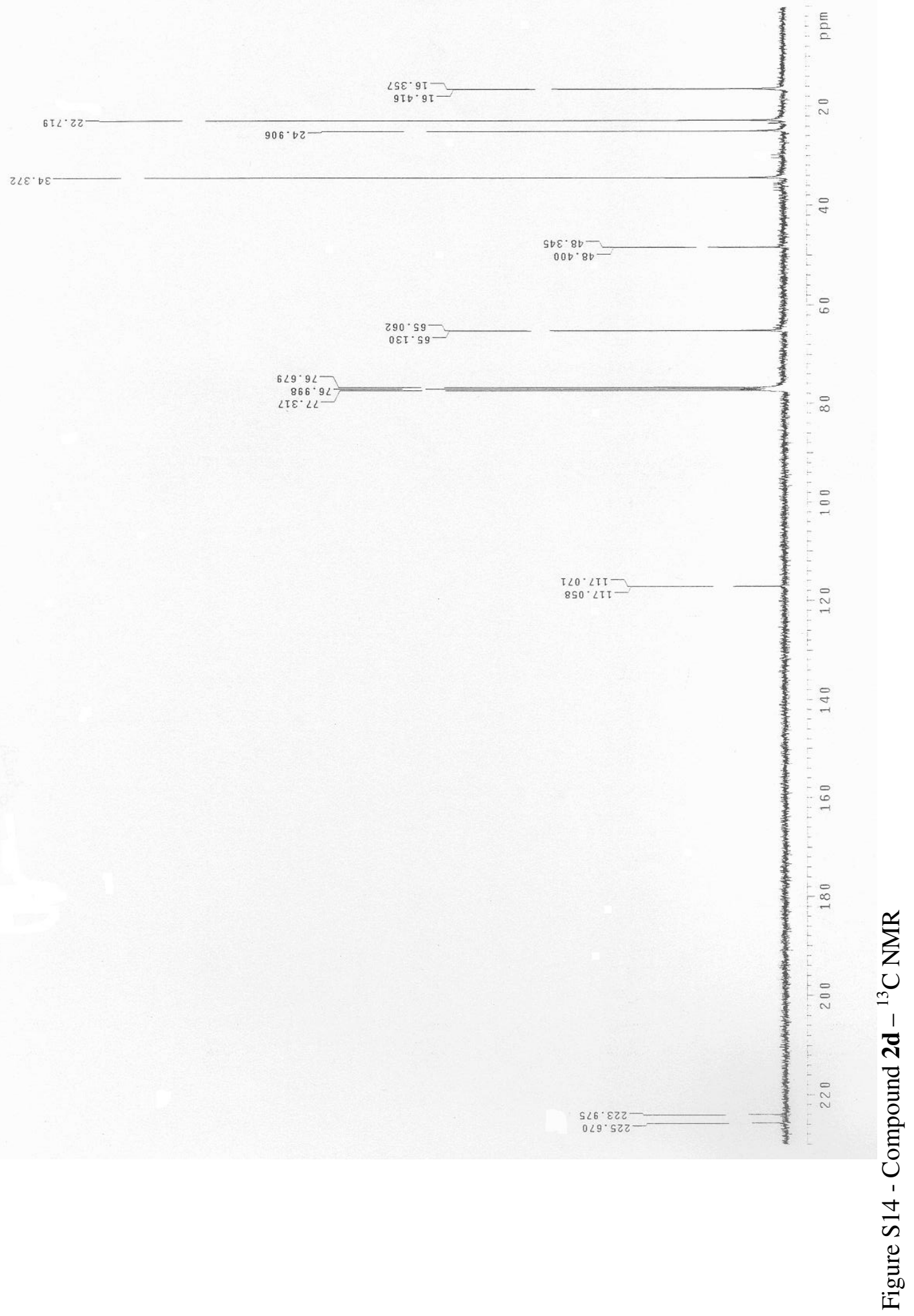

$\frac{ \pm}{\sim}$ 


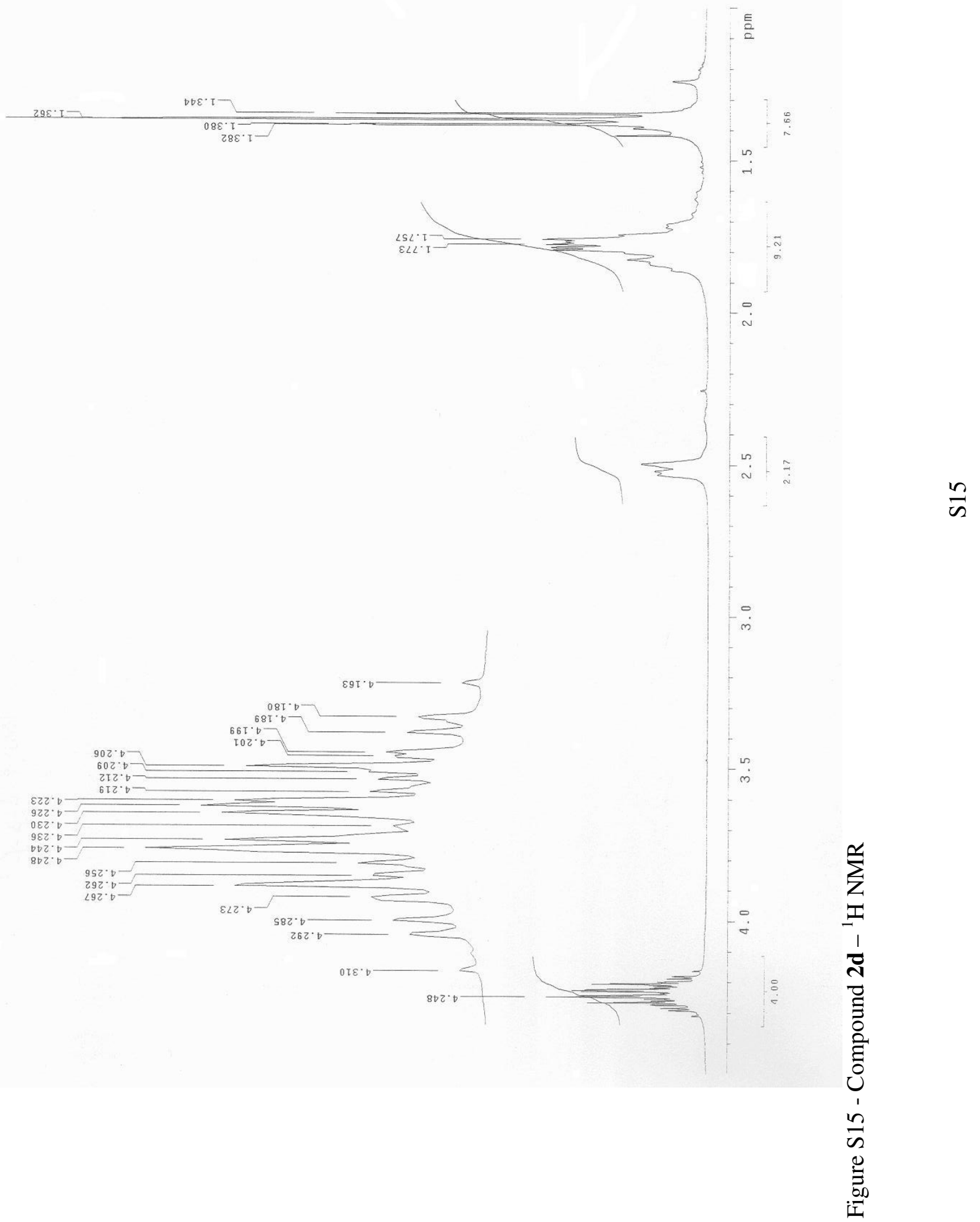




$$
t
$$




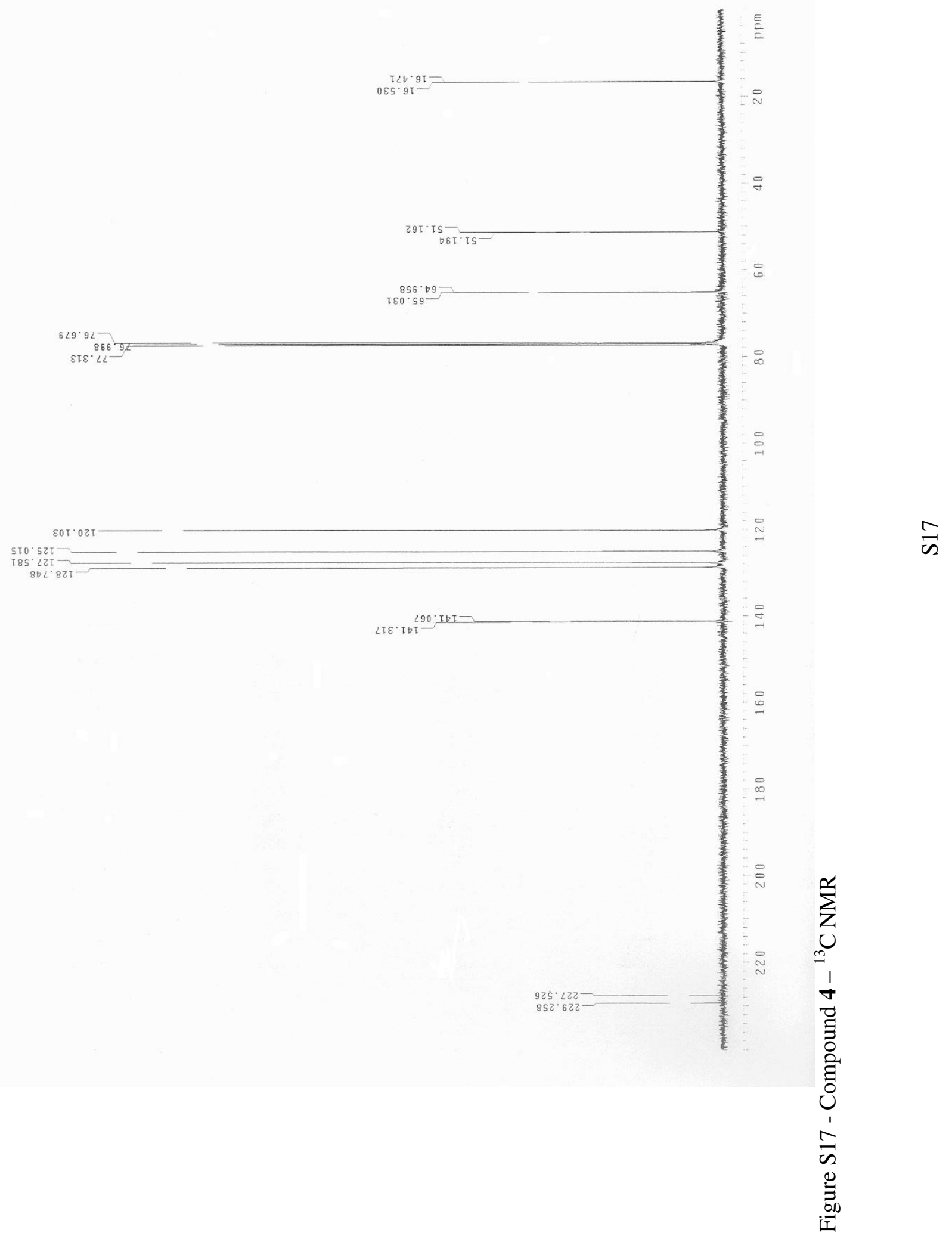




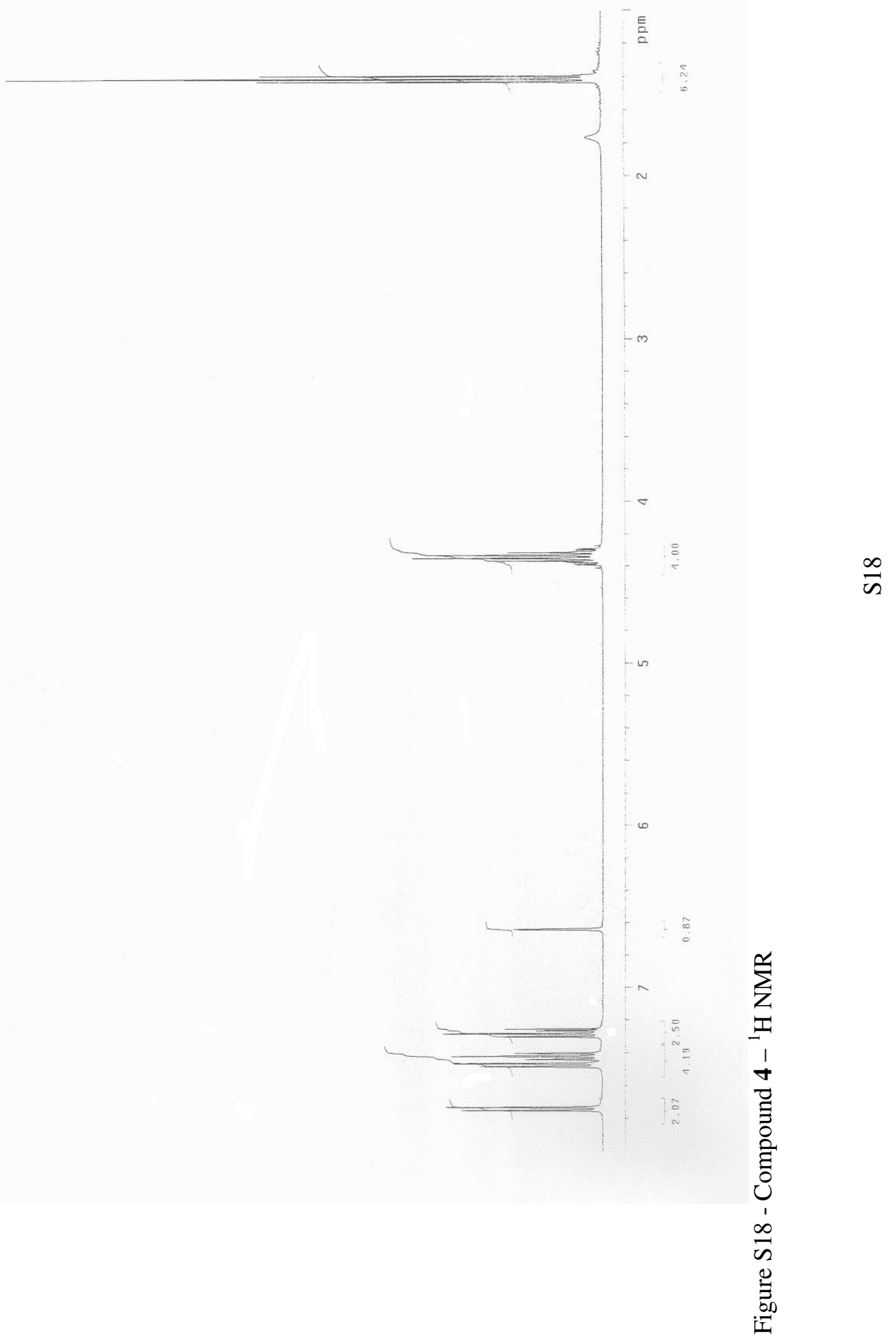




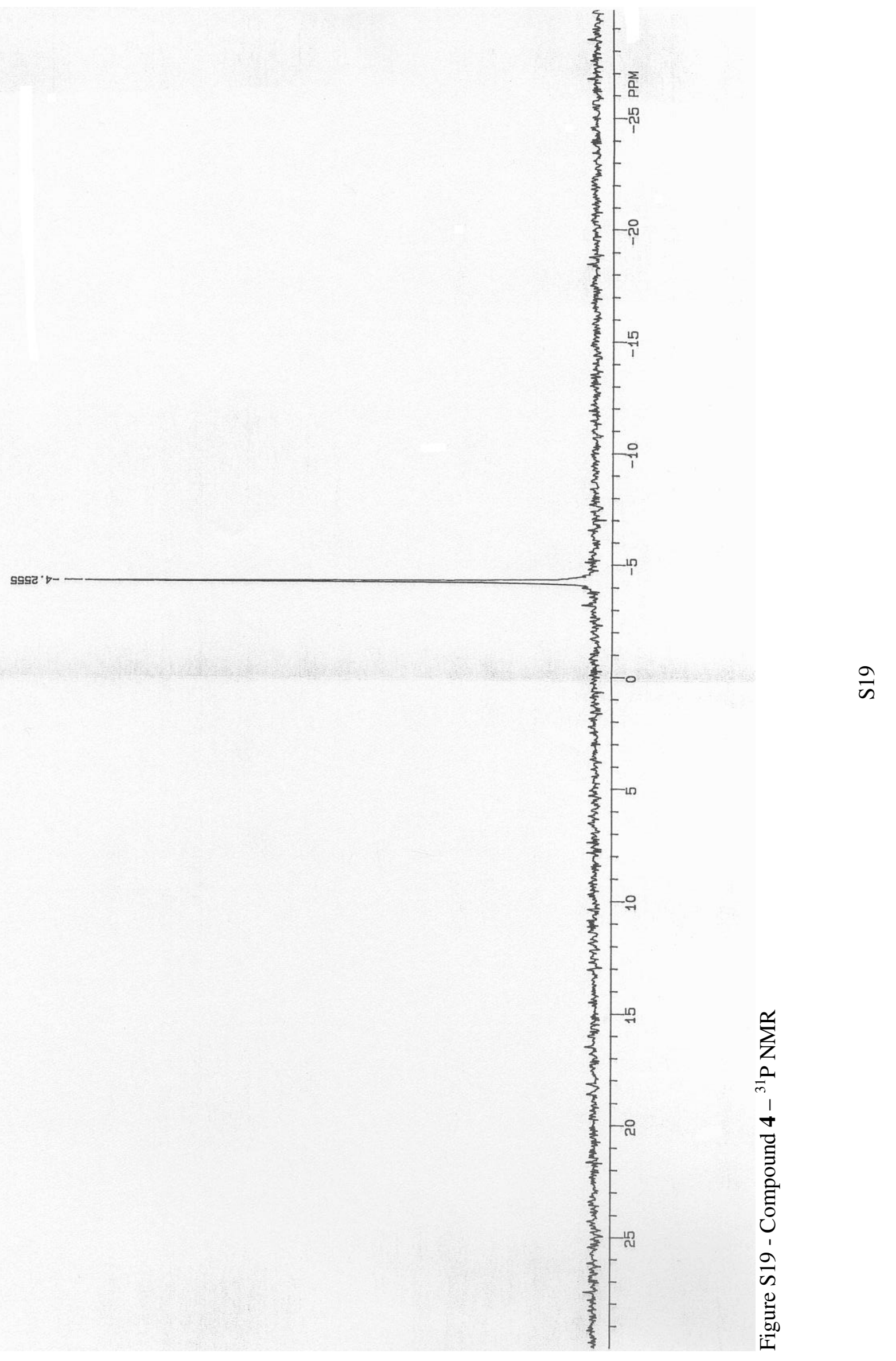




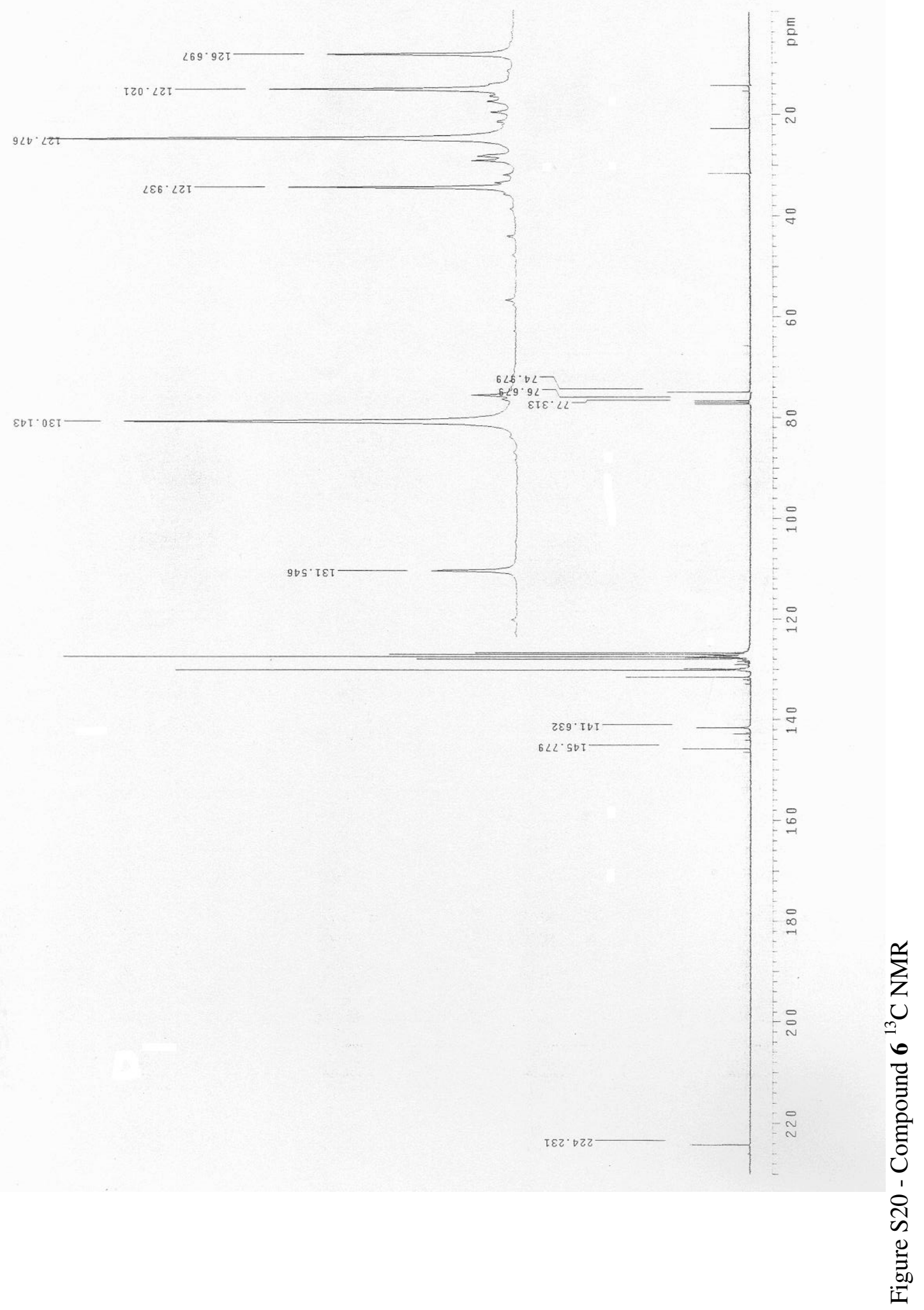




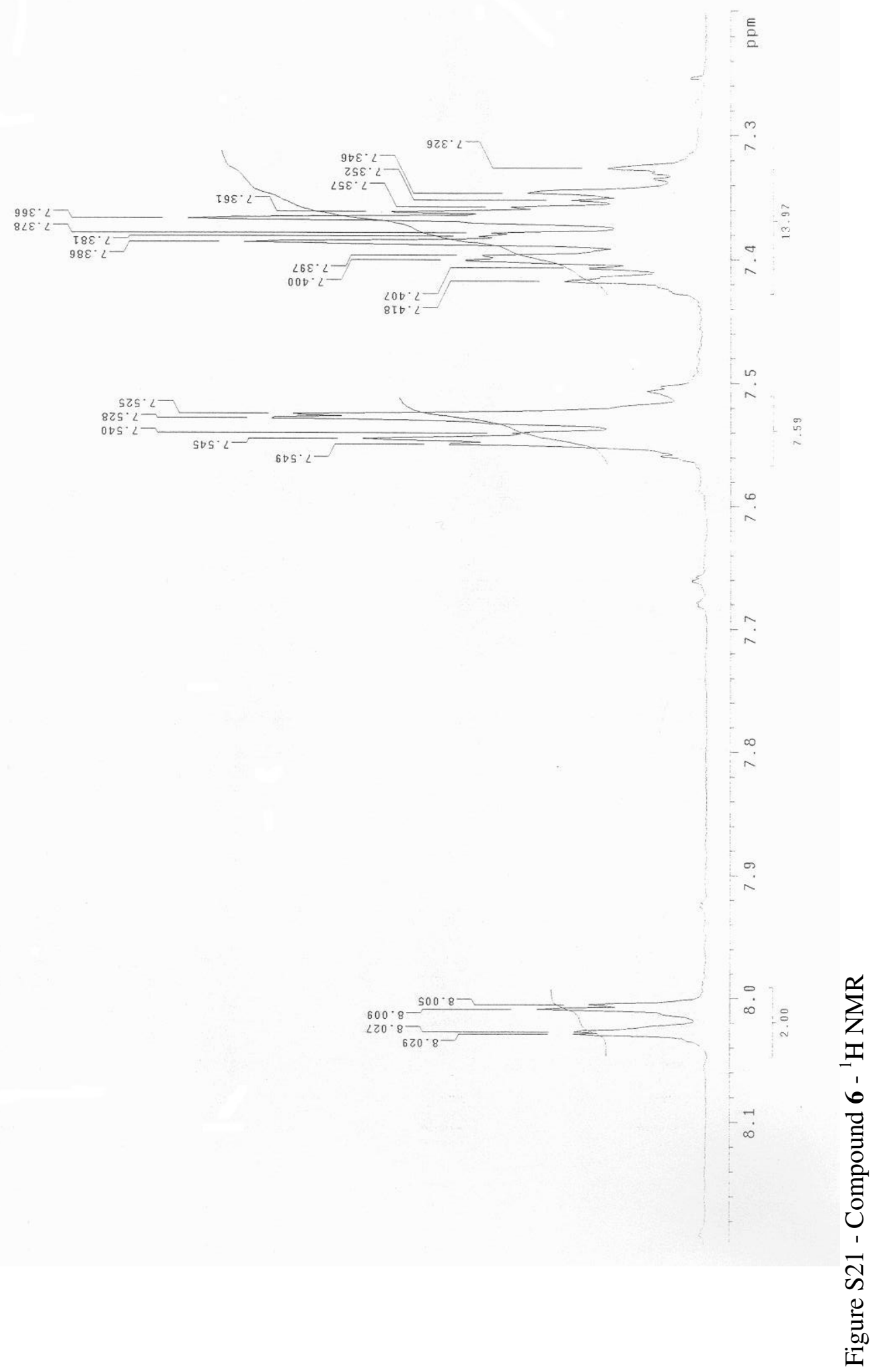

ฟิ

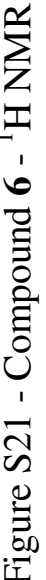

